\title{
Building interpersonal trust within organizations: a relational signalling perspective
}

\author{
Frédérique E. Six
}

Published online: 19 July 2007

(C) Springer Science+Business Media B.V. 2007

\begin{abstract}
This article develops the foundations for a theory of interpersonal trustbuilding based on relational signalling theory (RST). RST is based on the assumptions that rationality is bounded through framing, that preferences are partially determined by altruism (through a distinction between foreground and background goals), and that an individual's action is influenced by the normative context in which he or she operates. The focus is on interpersonal trust in work relations within organizations. Interpersonal trust-building is construed as an interactive process in which both individuals learn about each other's trustworthiness in different situations. Four conditions for the building of interpersonal trust within organizations are (1) the suspension of all opportunistic behaviour, or the removal of distrust; (2) exchange of positive relational signals; (3) avoiding negative relational signals, i.e., dealing with trouble; and (4) the stimulation of frame resonance, or the introduction of trust-enhancing organizational policies. The proposed theory can explain important characteristics of trust in organizational contexts, such as the interactive nature of trust, the learning required to build trust, the role of psychological mechanisms (such as attributions and perceptions) in decisions to trust, the limits to trust, asymmetries between trust and distrust and the contextdependency of trust.
\end{abstract}

Keywords Interpersonal trust-building - Organizational policies · Relational signalling theory $\cdot$ Trouble $\cdot$ Work relations

F. E. Six $(\bowtie)$

Department of Public Administration and Organization Science, VU University Amsterdam, Amsterdam, The Netherlands e-mail: FE.Six@fsw.vu.nl 


\section{Introduction}

It has often been argued that trust is essentially important for successful cooperation and effectiveness in organizations (Zand 1972, 1997; Deutsch 1973; Lewis and Weigert 1985; Zucker 1986; McAllister 1995; Lane 1998; Rousseau et al. 1998; Nooteboom 2002). Yet despite the general acceptance of this principle, experience to date-both academic and otherwise-has shown the difficulty of building and maintaining trust in such relations. Why should this be the case?

Three factors can be identified that make it difficult to build trust. In the first place, trust-building is an interactive process that involves (at least) two individuals learning about each other's trustworthiness; it takes two to tango (Zand 1972; Luhmann 1979; Zucker et al. 1996). The second factor is that the underlying systems dynamics of both trust and distrust are based on positive feedbacks, reinforcing the initial behaviour (Zand 1972; Deutsch 1973) but with an important asymmetry. Trust is built up gradually and incrementally, reinforced by previous trusting behaviour and previous positive experiences (Zand 1972; McAllister 1995; Lewicki and Bunker 1996); whereas distrust is more catastrophic (Lewicki and Bunker 1996; Lane 1998). The third factor is that there is no absolute certainty that the trust will be honoured (Luhmann 1979; Lewis and Weigert 1985; Gambetta 1988; Möllering 2001). Trouble inevitably arises as a result of the presence of radical uncertainty (Knight 1921), random lapses in efficiency (Hirschman 1970), short-term temptations or through mishaps (Lindenberg 2000). To date, no satisfactory explanation has been offered to account for these factors in the process of trust-building or of the possibility of trust. We need more knowledge of how trust-building works as an interactive process, of the way trust is built up in a context of problems and adversity and how organizational policies and settings affect the generation and maintenance of trust. The purpose of this article is to lay the foundations for a theory of interpersonal trust-building that will explain these characteristics.

Most theoretical writings on interpersonal trust have been mid-range theories, giving partial explanations based on relationships between constructs. The more fundamental theories take rational choice theory as their basic framework. However, a growing number of authors have pointed out that rational choice approaches are incapable of giving satisfactory explanations of trust (Tyler and Kramer 1996; Hollis 1998; Kramer 1999; Lindenberg 2000; Nooteboom 2002; Weber et al. 2005). Traditional rational choice approaches to trust are limited in their ability to explain important real-life features of interpersonal trust and these are especially salient when studying the interactive development of trust. They fail to provide proper explanations for the role of perceptions and attributions and the cognitive and affective bases of relational trust (McAllister 1995). The real-life evidence that individuals can be motivated by social and altruistic, other-directed, goals is also incompatible with rational choice theories on trust such as agency theory (Shapiro 1987) or transaction cost theory (Williamson 1993). Research has shown that rational self-interest alone is an insufficient basis for the development of interpersonal trust in work relations; the behaviour of the trustee- the individual wishing to elicit the trust of the trustor-must also be guided by the wish to promote 
the well-being of the trustor (Lindenberg 2000; Nooteboom 2002). This suggests that human behaviour is not purely guided by rational self-interest but is also guided by broader considerations (such as the desire to promote the well-being of other individuals or the collective), and that effective signalling of this intent is needed for trust to develop. Several models have been proposed to account for this behavioural situation, such as mixed motive situations (Schelling 1960), social dilemmas (Komorita and Parks 1995), social value orientation (McClintock 1972) or dual concerns model (Pruitt and Rubin 1986). However, these models do not address the relation between individual action and organizational policies. Relational signalling theory (RST), on the other hand, explicitly stresses the fact that human behaviour is largely guided by the social context in which the individual operates (Wittek 1999). $\mathrm{RST}$, as a result, is capable of providing a satisfactory theoretical basis for understanding the impact of organizational policies on interpersonal trust-building.

Several trust researchers have shown that relational signals play a crucial role in interpersonal trust-building (Bacharach and Gambetta 2001; Bottom et al. 2002; Hardin 2002; Kramer 1999; Pillutla et al. 2003; Weber et al. 2005). Trustors look for two things in the behaviour of trustees. First, they check to see whether the latter's behaviour indicates that he or she is competent to perform according to expectations. Second, trustors look for signs in the behaviour of trustees that the trustee intends to maintain the relationship of trust in the future: so-called relational signals.

In this article, a general description is first given of the assumptions and key implications of relational signalling theory before applying them to a theory of interpersonal trust-building. We conclude by reflecting on the strengths and limitations of the relational signalling approach to interpersonal trust-building and suggest further research.

\section{Relational signalling theory}

Relational Signalling Theory was first proposed as a theory by Lindenberg (1988, 1993a, b, 1997, 1998), followed by several empirical tests (Wielers 1997; Wittek 1999; Mühlau 2000; Wittek et al. 2003; Mühlau and Lindenberg 2003). RST is based on two basic assumptions: the first is that human behaviour is goal directed and that any effort to explain social phenomena must pay attention to the goals of the individual actors (Lindenberg 1997). The second assumption underpinning relational signalling theory is that human behaviour is context-dependent. These two assumptions will be considered in turn, firstly the implications of goal-directedness.

Individuals are rational, but their rationality is bounded, not only in the sense that they have too little information, but also with regard to their ability to make use of all the information at their disposal. This implies that, in general, in any given situation demanding action, individuals are sufficiently rational to pursue one goal, and to foreground this main goal in their attention (Lewin 1936). This main goal structures, or "frames"-i.e., gives a definitional frame to-the situation, while other potential goals are relegated to the background. The latter have only an indirect effect, as they only modify the degree to which the main goal structures the 
situation and determines evaluation and choice. The frame with which an individual actor approaches a particular situation can also be seen as a process that guides selective attention and is "triggered" by the salient goal (Gollwitzer and Moskowitz 1996; Kruglanski 1996). When a background goal is congruent with the main goal, it will have a positive, reinforcing effect on the salience of that goal and when a background goal is incompatible with the main goal it will have a negative effect.

Direct costs, related to the main goal, are much greater than opportunity costs, which are related to background goals. This is important for a theory of trustbuilding, because it allows the opportunity costs of honouring trust to vanish into the background, greatly reducing opportunistic tendencies when the normative frame is strong. Rationality is thus strongly bounded by the fact that the various potential goals do not have equal weight. An important implication of the framing of goals is that goals are not fixed in advance:

The image of a decision maker who makes choices by consulting a preexisting preference order appears increasingly implausible. The alternative image is of a decision maker who chooses reluctantly and with difficulty [...] and who constructs preferences in the context and in the format required by a particular situation (Kahneman and Tversky 2000, p. xvi).

In a given situation, the greater the involvement of the individual in the main goal, the more stable the frame. The frame stability will be higher when the main goal is tied to compatible emotions and to direct consequences for the individual him- or herself. There are two threats to the stability of an individual's frame. First, although human behaviour is seen as goal-directed, individuals are easily distracted by the seductions of short-term goals; they appear to find it difficult to resist such temptations even when they are against their own long-term interest (Mischel et al. 1996). This tends to makes frames fragile. Furthermore, frames can become weaker over time unless a special effort is made to maintain them (frame decay, e.g., Lindenberg 2000). Frames are also weakened by incompatible background goals. When a frame is excessively weakened there may even occur a frame switch, with the background goal assuming the defining role, with the original foreground goal being pushed into the background. This frame change will have a significant effect on the ordering of the alternatives considered for action.

The second assumption underpinning relational signalling theory is that human behaviour is context-dependent, depending on the frame that the individual is in. Lindenberg (2003) identified three master frames: hedonic frame, gain frame and normative frame. The main goal defining a hedonic frame is to feel good or better right now. It is thus a very short-term goal directed at states of the individual him- or herself, such as physical states (hunger, pain, excitement) and psychic or emotional states (sense of loss, fear, status, affection). The second type of frame, the gain frame, is defined by a main goal to improve one's resources. These resources may be material, for example money, or immaterial, such as improving one's competencies. This goal is also directly linked to the interests of the individual, but it is not an immediate goal either in time or in emotional terms. The third frame is referred to as a normative frame, when the main goal is to act appropriately. It is neither directly linked to the emotions nor to consequences for the individual 
him- or herself, since the hedonic and gain-related goals are now in the background, if present at all. The first two of these master frames can be called self-interested, since Ego (the acting individual) is only concerned with his own interest, while the third master frame is other-directed, as Ego will also show concern for Alter's (the other individual) interests. For the purpose of this study it suffices to recognize the distinction between the self-interested vs. the normative (other-directed) frame. This distinction is similar to that made in social dilemma, dual concern and mixedmotive theories (Schelling 1960; Pruitt and Rubin 1986; Komorita and Parks 1995). A priori, the self-interested frame would appear stronger than the normative frame and for this reason individuals interacting with each other may be justified in suspecting that the normative frame will give way to the self-interested frame. They will therefore look for signals in the behaviour of the other individual indicating the stability or instability of the normative frame. In other words, they will seek to discern the degree to which the other individual is still interested in maintaining the relationship. Such relational signals are "behavioural clues that allow us to make inferences about other people's interest in maintaining a mutually rewarding social relationship with us" (Wittek 1999, p. 8). A positive relational signal is any behaviour by a first individual that contributes to the well-being of the second individual. This usually entails a sacrifice on the part of the first individual and is perceived by the second individual as an indication of the stability of the first individual's normative frame. A negative relational signal is any behaviour by a first individual that decreases the well-being of the second individual, who perceives this as an indication of the decay of the first individual's normative frame. It is important to point out that the kinds of action that do or do not constitute relational signals is a question of the perceptions of the beholder (Wittek 1999). The same holds for the sign of the relational signal, i.e., whether it is perceived as positive or negative.

Attribution theory is relevant here as it focuses on "the extent to which an actor's behaviour provides information about his or her stable underlying dispositions" (Azjen et al. 1979, p. 1871; Kelley 1973). A trustor makes causal attributions about the observed trustee's behaviour and perceived relational signals, in other words, she determines whether the perceived signals are caused by a stable normative frame or not (Kelley 1973). If the causal attribution is that the trustee acted from a stable normative frame, the trustor is likely to conclude that the trustee is trustworthy. If the causal attribution is that the trustee acted from a self-interested frame or that situational factors caused the observed behaviour, then the trustor is less likely to conclude that the trustee is trustworthy. In the latter situation the relational signal will likely be perceived as negative.

Cognitive processes (including attribution processes) filter the perception of the signaller's behaviour, and subsequently influence the perceiver's response to that behaviour (Augoustinos and Walker 1995).

The notion of a relational signal reflects the insight that behaviour, interpersonal interaction and communication is not simply a matter of exchanging information, but also defines and adjusts the nature of the relationship between the individuals involved (Dillard et al. 1996). When signals significantly affect the interaction between two or more individuals they are usually accompanied by "expressions given off”, i.e., seemingly involuntary behaviour, like blushing or other body 
language (Goffman 1959). These are only partly open to manipulation (Frank 1988). This is important, since individuals who have little or no interest in a relationship can deliberately exploit relational signalling (Deutsch 1973). However, it is difficult for most people to pretend for long that they have good intentions when in fact they do not, as they will nearly always give off signals to the contrary.

An individual will have an interest in the stability of both her own and the other individual's normative frame, since losses can have serious negative consequences for framing and frame stability: loss aversion will be greater than gain achievement (Kahneman and Tversky 2000). This implies that she will tend to look for situations that will increase the stability of her own frame and avoid situations that will decrease the stability. One cannot choose a frame intentionally; it is a product of the main goal and the social context. Frames are part of the automatic cognitive processes that guide so much of our behaviour (Mühlau and Lindenberg 2003; Schneider and Shiffrin 1977; Shiffrin and Schneider 1977, 1984). Moreover, Lindenberg $(1998,2000,2003)$ claims that individuals are sensitive to the frames of those around them: there is "frame resonance". Individuals are more likely to act from a normative frame if people around them act from such a frame rather than a self-interested frame. Schelling's (1960) tit-for-tat strategy, Van Lange and Visser's (1999) "locomotion in social dilemmas" and Messick and Kramer's (2001) “conditional trustors" may be seen as supporting this claim. Latané and L'Herrou (1996) also show that the simple exchange of preferences in a network triggers a preference structure with people near each other developing similar preferences.

\section{Theory of interpersonal trust-building}

In this section we first define interpersonal trust and the trust-building process. We argue that a prerequisite for interpersonal trust-building is that both individuals involved have their actions guided by a stable normative frame. Thus the stability of normative frames becomes a joint goal. Four conditions for stabilizing normative frames are identified and these are discussed in turn.

\subsection{Interpersonal trust and the trust-building process}

Most definitions in the literature treat trust as a state, belief or positive expectation. The definition employed here is a combination of Mayer et al.'s (1995) and Rousseau et al.'s (1998) definitions: interpersonal trust is a psychological state comprising the intention to accept vulnerability to the actions of another party, based upon the expectation that the other will perform a particular action that is important to you. When individuals are placed in a relational context where trust is involved, trust and action must mutually reinforce each other. This is reflected in the perspective adopted in this article: interpersonal trust-building is a reciprocal process in which both parties are involved interactively in building trust. Most models in the literature are either static or take the perspective of the trustor only (for example, Mayer et al. 1995 and Ross and LaCroix 1996). Zand is one of the few who propose a truly interactive model: 
Let $\mathrm{P}$ denote one person and $\mathrm{O}$ the other. If (1) $\mathrm{P}$ lacks trust, (2) he will disclose little relevant or accurate information, be unwilling to share influence, and will attempt to control O. (3) Assume O also lacks trust, (4) perceives P's initial behaviour as actually untrusting, and (5) concludes he was right to expect P to be untrustworthy; then (6) he will feel justified in his mistrust of P. Since (7) P sees O's behaviour as untrusting, he (8) will be confirmed in his initial expectation that $\mathrm{O}$ would not be trustworthy and (2) $\mathrm{P}$ will behave with less trust than when he entered (Zand 1972, pp. 232-233).

The individual's predisposing beliefs are crucial, for they determine her initial attitude which in turn will influence action. The individual's initial beliefs will or will not be confirmed through the impact of her actions on the other person. If confirmed, the beliefs will appear as self-fulfilling prophesies (Zand 1972, 1997). In attribution theory, Kelley (1973) also argues that prior beliefs about causation affect the intake of information about the event observed. In short, trust-building is based on positive feedbacks. This implies the possibility not only of upward spiralling processes, but also of downward spiralling processes. In upward spiralling processes of positive experiences of trusting, A's trust in B is confirmed, that is, B acts reciprocally according to A's pattern of expectations and trust is increased. If A perceives B to be sufficiently trustworthy, A will act in a way that makes himself vulnerable to the actions of B; B in turn will perceive A's action as indications of A's trust-and hence A's trustworthiness - and will probably act according to A's expectations, which will be perceived as confirmation of A's initial trust (Fig. 1).

Trust is highly relevant when the trustor depends on the trustee's future action(s) to achieve her own goals and objectives (Lane 1998). This dependence implies that the trustor, when acting on trust, assumes a position that is vulnerable to opportunistic behaviour by the trustee. However, trusting another inherently entails the positive expectation that the trust will not be taken advantage of (Hosmer 1995; Whitener et al. 1998). Thus, for trust to develop, it is required that the trustee does not indulge in opportunistic behaviour, so that the trustor can put herself in a vulnerable position with regard to the action(s) of the trustee. This requires a stable normative frame. In other words, for trust to be possible, the trustor needs to believe that the trustee wishes to continue the relationship into the future (Lindenberg 2000;

Fig. 1 Interactive trust-building process (adapted from Zand, 1972)

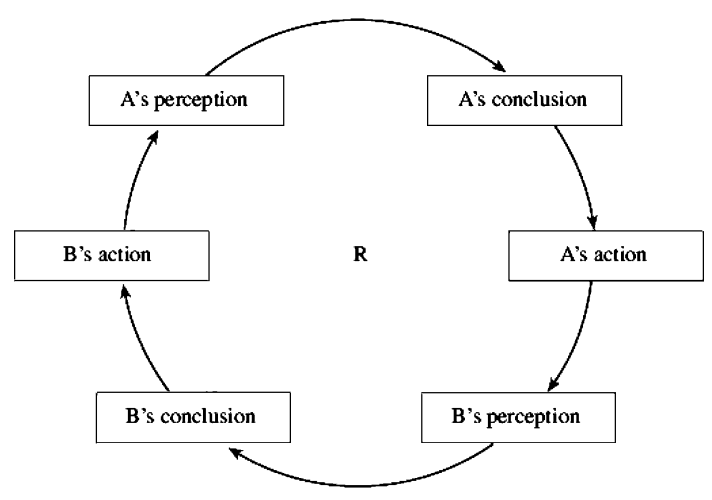


Hardin 2002). And since in interpersonal trust-building each individual is simultaneously trustor and trustee, both individuals need their actions to be guided by a stable normative frame.

Proposition 1 For interpersonal trust to be built in long-term work relations, both individuals need to have their actions guided by a stable normative frame.

The stability of normative frames becomes a joint goal and is likely to be jointly produced within the relationship itself through positive relational signals, as well as within the organization as a whole with the help of flanking arrangements that are part of the organizational context. One can identify four operative conditions that play an essential role in stabilizing normative frames: (1) the suspension of opportunistic behaviour, or the removal of distrust; (2) exchange of positive relational signals; (3) avoiding negative relational signals, i.e., dealing with trouble; and (4) the stimulation of frame resonance, or the introduction of trust-enhancing organizational policies. An organization needs to ensure all four conditions, but depending on the particular environment it operates in, the emphasis may differ. The more an organization meets all four conditions, the more likely it is that interpersonal trust can be built successfully in the work relations within it. Two of these conditions (2 and 3) act at the relationship level (dyadic level) and two (1 and 4) at the organizational level.

Proposition 2 For interpersonal trust to be built successfully within the organization, the organization needs to meet all four conditions for stabilizing normative frames.

Below, each of the conditions is described in more detail.

\subsection{Removal of distrust}

Distrust and trust are distinct, though related, concepts. Removing distrust is not the same as building trust (Lewis and Weigert 1985; Lindenberg 2000; Larson 2004). Lack of distrust is a necessary but not sufficient condition for building trust. Situations of legitimate distrust, defined as situations where "any explicit or implicit promise [...] is blatantly against the self-interest of the promising party" (Lindenberg 2000, p. 12), are highly likely to lead to actions of the potential trustee that are strategically opportunistic, that is actions such as lying, cheating and generally willing to hurt the other individual (the trustor). In such situations, distrust on the part of the potential trustor is not seen as a sign of ill will or abnormal riskaversion, but rather as legitimate, since both the opportunities and the incentives for opportunism are too high for the potential trustee reasonably to expect compliance. Everyone has a price (Nooteboom 2002). Because the distrust is seen as legitimate, that is, "reasonable observers would say that any other reasonable person put into this situation" would judge similarly, remedies can be relationally neutral, meaning that the distrusting individual can "claim the necessity of remedies, pinpoint a menu of solutions and show good faith at the same time" (Lindenberg 2000, p. 12). The solution will focus on the alignment of interests, for example through credible commitments, reputation effects or third parties. 
Proposition 3 Before two individuals can begin to build trust, legitimate distrust situations must first be sufficiently reduced through interest alignment arrangements.

It should be noted that, in this perspective, the often used notion of calculative or deterrence-based trust (for example, Lewicki and Bunker 1996; Rousseau et al. 1998) is not trust, but rather a lack of distrust. When the blatant self-interest of the potential trustee is sufficiently reduced, there may still be room for opportunism of a different sort when short term and longer term interests point in opposite directions, generating a short-term temptation to break the trust (myopic opportunism).

How does this relate to framing and relational signalling? First of all, a normative frame will largely exclude the opportunistic behaviour promoted by the selfinterested frame; and the absence of opportunistic behaviour is a crucial condition for the trustor to place trust in a trustee. Therefore, the trustor will be looking for relational signals indicating the presence and stability of the trustee's normative frame. In situations of legitimate distrust, gain becomes the foreground goal, leading the trustee into a self-interested frame and making it highly likely that he will act in a strategically opportunistic way since all the restraints on that opportunism-relational and normative considerations-can only come from goals that have been pushed too far into the background to be capable of affecting the trustee's actions. Only if the interests of both are better aligned can the strength of the gain goal be sufficiently reduced for the normative goal to predominate and guide the trustee's actions.

Having thus dealt with the temptations for strategic opportunism, one must turn to the temptations that arise from myopic opportunism-that is, from random, purely situational temptations. Myopic opportunism is particularly likely to occur where a normative frame is especially needed: in situations where the desired behaviour cannot be prescribed in detail and where detailed control of performance is costly; in other words, in most contemporary organizations. If an individual allows himself to be guided by myopic opportunism, he is likely to cause the other to experience loss. This experience of loss is likely to trigger strong emotions, which in turn may cause a frame switch in the other individual to a self-interested frame where the main goal will be to redeem that feeling of loss. Moreover, if there are no obvious options for restoring the loss (or to "exit" the relationship), the second individual is likely to resort to "getting even" in order to balance this feeling of loss (Bies and Tripp 1996; Lindenberg 2000). An individual thus has a self-interest in avoiding myopically opportunistic actions, since this would trigger a switch to a self-interested frame in the other individual, who may then try to get even with him.

In the context of an organization, the possible arrangements for promoting interest alignment include performance-related bonuses or other rewards that stimulate team efforts rather than individual effort alone; or a clear code of conduct (with sanctions) that stresses cooperative rather than opportunistic, self-interested behaviour.

\subsection{Building trust}

To enhance the stability of their normative frames, individuals can act in a reaffirmative manner, i.e., they can act in a trustworthy manner and the best way to 
do that is by acting in a trusting manner (Zand 1997). In other words, the actions of the individuals will give off positive relational signals.

Proposition 4 The more positive relational signals are given off by both individuals, the more easily is trust built.

The concept of relational signals has deep implications for a theory of trust. As explained earlier, whether an action contains a relational signal and what kind of signal is determined by how the receiver of the signal (= trustor) perceives it and not what the sender (= trustee) thinks he has done. An action may be perceived to contain both positive and negative relational clues, generating four types of relational signals in general, depending on the presence or absence of positive and negative relational clues (Fig. 2). When neither a positive nor a negative relational clue is perceived by the receiver, the overall relational signal is "neutral". This is most likely to occur when the receiver is in a gain frame and considerations of solidarity have receded into the background, because in such situations she is not concerned with maintaining the relationship (and therefore, she is also not concerned with trust). When only positive relational clues are perceived, the overall relational signal is "unambiguously positive", and similarly when only negative relational clues are perceived it is called "unambiguously negative". However, it is likely that quite frequently the receiver is not entirely clear about the overall signal since both positive and negative clues are perceived. This is called an "ambiguous" relational signal and could be due to causal ambiguity (Nooteboom 2002), noisy environments (Van Lange et al. 2002; Tazelaar et al. 2004), attribution errors (see below) or Weber et al.'s (2005) motivated attributions by the trustor. The verbal and non-verbal actions of the sender may appear to contradict each other. The sender may think he should trust the receiver, while in his subconsciousness he does not trust him, with the result that conflicting signals are sent and (probably) received. Ambiguous relational signals may also occur when someone is perceived not to "walk his talk" or when he behaves inconsistently; or intends well but is not sufficiently skilled to execute the action that is supposed to send the unambiguously positive relational signal. Given the vulnerability involved in trust-building, when the trustor perceives an ambiguous relational signal, she is more likely to err on the side of caution, which implies that she is more likely to interpret the action as conveying a negative relational signal. This in turn will hinder the trust-building process.

Fig. 2 Types of relational signals

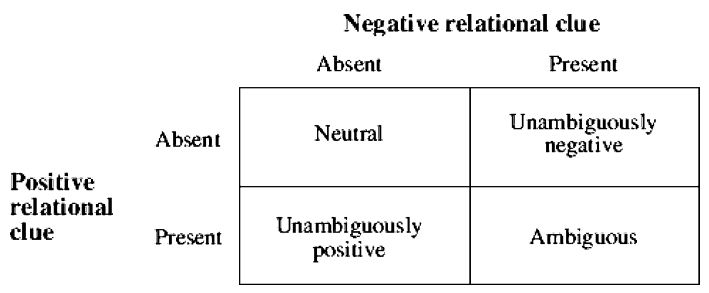


Proposition 5 The more ambiguous a relational signal, the more likely it will be treated as a negative relational signal.

It may even be more important to ensure that negative relational clues are absent than that positive relational clues are present. In general, the ambiguity of the relational signal is probably reduced the more both trustor and trustee are aware of their true attitude toward the other, have self-confidence (without arrogance; Deutsch 1973), self-discipline (Mischel et al. 1996) and a high level of interpersonal skills (Johnson and Johnson 1995).

Proposition 6 The more both trustor and trustee are aware of their true attitude toward the other, have self-confidence, self-discipline and a high level of interpersonal skills, the more likely that ambiguity of the relational signal will be avoided.

As Eckel and Wilson (2004) have observed, trust is a problem of judgment under uncertainty, not a problem of risk. Tversky and Kahneman (1974) identified three heuristics that guide our judgment under uncertainty, and as argued earlier, deciding whether to trust or not to trust takes place in situations of uncertainty. These three heuristics-representativeness, availability and anchoring and adjustment-lead to biases that in turn affect the way relational signals are received (the perceptions and conclusions in Fig. 1). First, the representativeness heuristic "in which probabilities are evaluated by the degree to which $\mathrm{A}$ is representative of $\mathrm{B}$, that is, by the degree to which A resembles B" (Tversky and Kahneman 1974, p. 1124). This can have implications for the trustor's perception of the trustee's trustworthiness, as the former becomes insensitive to sample size; misconceives chance and regression; and falls for the illusion of validity of her perceptions and her interpretation of the trustee's relational signals. Second, availability: individuals tend to assess the probability of an event by the ease with which instances or occurrences can be brought to mind' (Tversky and Kahneman 1974, p. 1127). The relevance for issues of trust is that the more vivid, recent or emotion-laden, the more readily available the memories tend to be. This may bias the interpretation of the relational signal. In particular, experiences of betrayal are usually more vivid and thus more readily influence decisions of whether or not to trust (Ross and LaCroix 1996). Finally, the anchoring and adjustment heuristic biases our judgment by the starting point we take for it, because subsequent adjustments from that initial value "are typically insufficient" (Tversky and Kahneman 1974, p. 1128). This can explain why initial judgments about the other person's trustworthiness are frequently insufficiently adjusted when new information becomes available (Azjen et al. 1979). Another psychological mechanism that may be at work in trust decisions is Staw's (1976) "escalation of commitment". Staw found that "people [...] may have a tendency to get stuck in losing courses of action" (Staw 1997, p. 193). These so-called escalation situations exist when (1) losses have been suffered, (2) there is an opportunity either to withdraw or persist and (3) the consequences of these actions are uncertain (Staw 1997, p. 192). If a trustor has experienced trouble in which she has suffered a loss, then she has the opportunity to persist, i.e., continue to trust, or withdraw from the relationship. The consequences of these actions are uncertain, as the trustor cannot be sure of the trustee's trustworthiness in the future. It may be that 
when choosing to persist, her trust will be betrayed and she again may suffer losses. On the other hand, though this is difficult to know, the trustee may indeed be trustworthy, in which case the trustor's withdrawal will result in gains foregone.

Attribution theory also predicts several cognitive biases. First, there is the fundamental attribution error, where a problem is attributed to an individual rather than to the system or situation (Ross 1977). Second, according to Moon and Conlon (2002) there is the "person sensitivity bias": a "person positivity bias" exists under positive performance conditions (as found earlier by Sears 1983) and a "person negativity bias" exists under negative performance conditions. "Individuals get too much credit when things go well and too much blame when things go poorly" (Moon and Conlon 2002, p. 33). Finally, Robbins et al. (2004) concluded from experiments with unfamiliar individuals in relatively brief interactions where the emotional stakes were low, that people are consistent in the way they perceive and explain (attribute) behaviour, regardless of the particular interaction situation or the particular individual whose behaviour is judged. This suggests that it is "general schemas, such as implicit theories, [that] drive causal attributions" (Robbins et al. 2004 , p. 341), rather than complex, person- and situation-specific models, such as proposed, for example, by Mayer et al. (1995). However, the validity of these findings for real-life, long-term work relationships is questionable. As Mayer et al.'s model (1995) suggests, as long as very little specific information is available, the trustor will rely more strongly on generalized schemas, such as her general propensity to trust, whereas, the more information becomes available, the more she will rely on person- and situation-specific information, such as her perceptions of the trustee's trustworthiness. Third-party effects will also influence and speed up this process (Ferrin et al. 2006).

It is likely that the more aware both trustor and trustee are of these psychological mechanisms and the attributions they make as a result, the more likely it is that ambiguity in the relational signal can be avoided. And when the resulting unambiguous relational signal is positive, then trust can be built interactively. When A perceives an ambiguous relational signal in B's action that leads her to be more hesitant in her action towards B, this can set in motion a vicious cycle of further ambiguity and more hesitancy, which, given the asymmetries in trust and distrust, can easily lead to distrust and rupture of the relationship.

Interpersonal trust-building requires that two individuals open themselves up to social influence (Zucker et al. 1996) and learn about each other's trustworthiness. Experience, be it direct or indirect through third parties, is the most important route for building interpersonal trust (Lewis and Weigert 1985; Lewicki and Bunker 1996; Rousseau et al. 1998). As the trustor forms her decision to engage in interaction with the trustee (or not), she will examine the information she has at her disposal. In the extreme case, where there is no information of any sort, there is no basis for trust. Lewis and Weigert (1985, p. 970), referring to Simmel, claim that trust is only relevant when there is "a degree of cognitive familiarity with the object of trust that is somewhere between total knowledge and total ignorance...". When there is total knowledge, there is complete certainty, and thus no need for trust. When there is total ignorance, or no knowledge whatever, there is no reason to trust: "taking a gamble" would be the appropriate expression. However, Hardin (1993) 
claimed that there is nearly always at least some cognitive familiarity, even if not at the personal level. Information of some sort, either directly through interaction with the trustee or indirectly from third parties or from the context within which the interaction takes place, is always available. The information comes to us through all the senses: hearing, seeing, smelling, feeling, and so on. It is then processed to form a cognitive and emotional base for trust (Lewis and Weigert 1985). Much of this is done unconsciously (Nooteboom 2002), through automatic processing (Schneider and Shiffrin 1977; Shiffrin and Schneider 1977, 1984). I may be more likely to trust an hitherto unknown stranger if he smells like someone I trust; I may be more likely to distrust an hitherto unknown stranger if he looks like someone who cheated on me; but I will probably not even be aware of these processes. We probably always have information of some sort available to us, and at the same time we normally do not have access to a complete knowledge of others or their motives.

The interactive trust-building model depicted in Fig. 1 is a reinforcing loop because the underlying system dynamics are based on positive feedbacks. However, if that were the whole story, the level of trust that could be reached would be infinite. Since this is not what happens in real life there must be balancing elements that have not yet been identified. In reality, few people would suggest that any individual can be trusted in all respects under all conditions. There are limits to everyone's trustworthiness. A general limit to trust is formed by the a priori potential strength of the self-interested frame over the normative frame and the potential presence of "legitimate distrust situations". Thus the central issue in trustbuilding is "how well do I know under which conditions I can trust him to do what" rather than "the more I can trust him the better it is" (Gabarro 1978; Six and Nooteboom 2003). It is therefore important to distinguish different dimensions of trustworthiness.

Of the many different dimensions of trustworthiness identified in the literature, a distinction is commonly made between competence or ability on the one hand, and intention on the other (for examples see Barber 1983; Nooteboom 2002). The dimension "intention" can be further sub-divided into benevolence (Mayer et al. 1995), dedication (reliability, commitment or making an effort as defined by Nooteboom 2002) and norm-acceptability (the acceptability of one's own principles; Mayer et al. (1995) refer to this as moral integrity). The potential limits to a person's trustworthiness can be identified. First, with reference to the dimension of ability, no one is perfectly competent in all respects. Second, with regard to benevolence, there are situations where distrust is legitimate, since everyone has a price; and third, with reference to dedication, no one consistently "walks their talk" all of the time and in all respects; we occasionally fall prey to short-term temptations. Finally, concerning norm-acceptability, it is rare for two individuals to have complete norm-congruence. What is acceptable behaviour is not a matter of black and white, but of many shades of grey, and this may cause disagreements about the acceptability of some norms. The normative frame, in the relational signalling approach, is defined by the goal "to act appropriately". What is "appropriate behaviour", however, is culture-dependent. 
Proposition 7 In interpersonal trust-building, four dimensions of trustworthiness can be distinguished: ability, benevolence, dedication and norm-acceptability.

The task then, when building trust as a trustor is to learn as much as possible about the trustee, gaining as realistic a picture as possible of his likely behaviour under different conditions. This learning will largely be based on a combination of the actual outcomes achieved and the relational signals perceived. The trustor may have some influence on the trustee's behaviour in the sense that some parts of the trustee's behaviour can be negotiated (Gabarro 1978). The trustee's task in this trust-building enterprise is to be as clear and unambiguous as possible about the conditions and actions he wants to be trusted in. As Deutsch (1973) has pointed out, if the trustee is in a self-interested frame (s)he has an interest in pretending to be in a normative frame and will therefore try to send positive relational signals. The notion of "expressions given off" however indicates the fact that in practice this may be difficult to get away with for long (Goffman 1959; Frank 1988). Even better, the trustee can help the trustor get the most realistic picture by indicating openly where some of the limits of his own trustworthiness are.

Trust-building involves attributions of causality and responsibility. The causal analysis of normal events, where expectations are met, occurs virtually all the time during interactions (Fincham and Bradbury 1987). The cognitive processes involved are usually automatic (Schneider and Shiffrin 1977; Shiffrin and Schneider 1997, 1984). However, when something unusual, abnormal or unexpected happens, the causal analysis often becomes a consciously controlled process, because the automatic processing breaks down (White 1988). This will be the case, for instance, when trouble arises.

\subsection{Dealing with trouble}

When trust runs into trouble, the flow of expectations is disrupted. Initially, at least, this is an unpleasant surprise. Thus, both trust and trouble are concerned with patterns of expectations. With trust, the pattern of expectations is satisfied, whereas with trouble the pattern is disrupted. When trouble occurs, the immediate temptation is to jump to the conclusion, "you see, he cannot be trusted", without first considering or investigating what actually happened. Consistency or balance, attribution, and evaluation (Argyris 1970) are three basic human tendencies. At such times, the individual is likely to question — at least temporarily — the stability of the troublemaker's good intentions and commitment to maintaining a fruitful relationship. The individual who is confronted with trouble caused by another's behaviour is likely to experience negative affect and uncertainty regarding that behaviour. This is likely to lead to emotional activity, designed to deal with the negative affect and feelings of betrayal; and to cognitive activity, such as attribution and assessment of the degree to which trust has been violated (Lewicki and Bunker 1996). Research on expectancies and attributions has shown that the disconfirmation of expectanciestrouble in our terminology-leads to more vigorous attributional thinking (Olson et al. 1996). In addition, unexpected nonverbal behaviours are more likely to be attributed to dishonesty and attempts at deception (Bond et al. 1992). 
In the event of such trouble, does the individual jump to conclusions about the cause of the trouble, or does (s)he suspend judgment (McEvily et al. 2003) until inquiry has been made into the background of the trouble situation? After all, there are many potential causes of trouble, such as a mishap, a misunderstanding, a mistake, a disagreement, gross incompetence or malicious intent; and only some of these causes would justify distrust. A violation of expectations

produces a sense of disruption of trust, or profound confusion, but not inevitably of distrust. Distrust only emerges when the suspicion arises that the disruption of expectations in one exchange is likely to generalize to other transactions. To distrust, then, implies an attribution of intentionality that continues throughout all interactions or exchanges, at least of a particular type (Zucker 1986, p. 59).

Wittek (1999) has shown that the essence of effective informal control-in other words, dealing with trouble-is that the controlling actor should act in ways that are not perceived by the target individual as negative relational signals. However, the impact of the trouble on the trust in the relationship requires more than merely the controlling individual avoiding negative relational signals; the target individual's reaction to the controlling individual's action should also not be perceived as a negative relational signal. Otherwise the controlling individual will feel that his uncertainty about the other's behaviour is confirmed:

Proposition 8 When two individuals find themselves involved in a trouble situation, the more they act in ways that are not perceived by the other as negative relational signals, the more likely it is that damage to the trust in the relationship will be avoided.

Constructive actions undertaken by both individuals can reduce the negative impact of trouble to a merely fleeting impression and make the ensuing trust more resilient than trust that has never been tested by trouble. On the other hand, negative and ambiguous actions by one or both individuals can easily lead to unwarranted distrust (Hardin 2004) and the level of trust subsequently failing to meet its "potential". An interactive trouble model thus evolves with the same elements as the interactive trustbuilding model shown in Fig. 1: B's action is perceived as trouble by A-the trustorwho may immediately jump to conclusions or suspend her judgment. She may or many not decide on an action. B-the troublemaker and trustee-observes A's action and decides either to react or not. This may lead to A taking another action and the cycle may thus be repeated. At some point A will evaluate this specific trouble event and draw a conclusion about its overall impact on the trust in the relationship. When A experiences trouble, regardless of the potential cause, she is likely to question - at least temporarily-whether the troublemaker is still interested in maintaining a mutually rewarding relationship. The actions she takes subsequently are likely to be aimed at finding out why the trouble occurred and at trying to make sure it will not recur. The first aim is only possible if $\mathrm{A}$ is able to suspend judgment, contain the negative impact and is open to social influence from the troublemaker (or a third party). This would be consistent with the learning stance advocated in this article. 
In order to model trouble effectively and comprehensively, affective and cognitive (attributional) processes, as well as characteristics of the specific relationship, the nature of the trouble event and the larger social context (including effects of third party relationships; Ferrin et al. 2006) will all have to be taken into account. The key questions that the trustor who experiences trouble needs to answer are (1) why did the trouble occur (a question of attribution), (2) can the trouble be resolved (a matter of efficacy) (Fincham and Bradbury 1987); and (3) what is the appropriate level of trust? Research into the attribution question suggests that even though the affective judgment system responds rapidly, mitigating information supplied directly after a trouble event can still affect the slower cognitive system. But once the cognitive processes have led the individual to a decision about the attributions and intentions, then any further information will need to be very powerful to have any effect (such as a new provocation; Azjen et al. 1979; Kremer and Stephens, 1983). But there is also the question of the cause of the trouble. A distinction between causal judgments, which influence responsibility judgments, and which may in turn influence blame judgments, highlight the different points of impact of the ability vs. the intentions dimension of trustworthiness (Fincham and Bradbury 1987). If the trustor judges that the trustee's lack of competence was the cause of the trouble, then judgments of responsibility and blame will probably be very different than when the trustor judges that the trouble was caused by the trustee's malicious intent. In addition, this judgment based on (a lack of) competence will influence the degree of effort that the trustor will invest in changing the situation for the better.

Most of the cognitive biases mentioned so far will lead the trustor to distrust more often than is warranted. The "escalation of commitment" bias is an exception. Indeed, it tends to get the trustor bogged down in misplaced trust. Staw's (1997) temporal model of escalation shows how the social and psychological processes involved may be strong enough to induce trustors to continue their trust in a trustee even when the trustee repeatedly causes trouble and, worse still, repeatedly violates the trustor's trust. In his third phase, Staw proposes that external, contextual forces are needed in the form of outsiders to help the trustor to break out of situations where continued trust is misplaced and distrust is warranted. Crucially, Staw assumed in his model "that behavioural forces must match or exceed the strength of any negative economic data in order to hold [decision makers] in a losing course of action" (Staw 1997, p. 209).

\subsection{Introducing trust enhancing organizational policies}

The fourth and final condition for stabilizing normative frames is by stimulating frame resonance. Like the first condition, this is a question of the organizational policies rather than any actions at the dyadic level. Because of frame resonancethe fact that one individual's frame will influence the frame of another in his vicinity - an individual has an interest in the social context in which he operates. Trust-enhancing organizational policies can be introduced to promote resonance of the normative frame. 
In general, the social context in which an individual acts affects the relative benefits accruing from different actions. An individual's behaviour will therefore normally be guided by the social context in which he operates; but it is not determined by it, as individuals retain a degree of freedom of choice, they can choose to obey the rules and norms or to break them (for example, Coleman 1990; Archer 1995). If an organization's management wishes to promote interpersonal trust-building in the organization, then a combination of three types of organizational policies can be effective:

1. By creating a culture in which relationships are important and in which showing care and concern for the other person's needs is valued (relationship-oriented culture);

2. Through normative control rather than bureaucratic control, because acting appropriately is the goal in normative control;

3. Through explicit socialization to make newcomers understand the values and principles of the organization and how "we do things around here".

With regard to the first of these policies: by explicitly formulating and implementing the norms and values relevant for operating within it, an organization can foster a climate of trust between its personnel (Schein 1992). This is also likely to enhance the resolution of trouble when it inevitably occurs. From the perspective of relational signalling theory, the norms and values would have to identify what is appropriate behaviour within the organization, which includes "showing other regard". Many authors have shown that a homogeneity of norms and values facilitates trust-building (for example, Zucker 1986; Lane 1998), resulting in a higher predictability and reliability of the trustee's behaviour. Strong homogeneity denotes a strong culture. But if the accepted norms and values include opportunistic behaviour, the strength of an organization's culture may not be a sufficient condition for building trust; the centrifugal forces will be too strong to hold the organization together.

The degree to which members of the organization feel that they are treated fairly or justly is also part of this first organizational policy. Organizational justice, including procedural as well as distributive justice, has been shown to be important in getting employees to trust their leaders (Greenberg 1990; Korsgaard et al. 1995). Korsgaard et al. (1995) found that the perceived fairness of decision making procedures fully mediated the impact of consideration shown by a team's leader for the member's viewpoint, on the member's trust in that leader. The group value model (Tyler 1989) is one of the suggested explanations for why the effects of procedural justice occur. This model is based on a view of the way individuals interact and what they seek from those interactions that is not unlike the account given here of what individuals in a normative frame seek: that is, the view that people in organizations value long-term relationships, norms and procedures that promote solidarity among organizational members.

Justice theory accords with Tsui et al.'s (1997) finding that trust in co-workers is greater when employers over-invest in their employees or when employers and employees mutually invest in the employee-organization relationship. When employers invest in that relationship beyond a purely economic exchange approach, 
they are more likely to be perceived by employees as showing care and concern for employees, i.e., perceived as sending positive relational signals. Interestingly, Tsui et al. show that this increases trust not only in the employer but also among coworkers.

Second, the ways in which people are controlled is important to the dynamics of trust-building. Control is often defined as the process of regulating other people's behaviour in order to make it more predictable (Zand 1997; Das and Teng 1998). The current literature is contradictory regarding the relation between trust and control, whether these are strictly alternatives or complementary (Bradach and Eccles 1989; Ring and Van de Ven 1994; Das and Teng 1998; Knights et al. 2001; Wells and Kipnis 2001). In a relational signalling approach, it is the relational signal of the control mechanisms that is most relevant. Here, the important distinction is between external measure-based control and internal value-based control (Eisenhardt 1985). The former, often called bureaucratic control, is based on "the establishment and utilization of formal rules, procedures and policies to monitor and reward desirable performance" (Das and Teng 2001, p. 259). Bureaucratic control, enforcing obedience to the company rules (Kunda 1992), is based on the underlying assumption that subordinates cannot be trusted because human beings are lazy and must therefore be supervised (Hoogervorst et al. 2004). Therefore, they cannot be granted full autonomy in deciding what is best for the organization. That is, bureaucratic control implies lack of trust (Das and Teng 1998) or even suspicion (McEvily et al. 2003). When control means the enforced obedience to the company rules, with penalties for disobedience, then the controlling action will probably be perceived as a negative relational signal and will in turn probably lead to distrust (or at least to a low level of trust). Thus, strong bureaucratic control is correlated with low trust and possibly even with high distrust.

Internal value-based control, or normative control (Kunda 1992; Das and Teng 2001), "relies on the establishment of organizational norms, values, culture, and the internalisation of goals to encourage desirable behaviour and outcome" (Das and Teng 2001, p. 259). An organization's members are driven by internal commitment, strong identification with company goals and by the intrinsic satisfaction of their work. It has been argued that the underlying assumption in this form of control is that "people can ultimately determine their own behaviour ... Since there is no explicit restriction on members' behaviour, more interpersonal respect and less mistrust are implied" (Das and Teng 1998, p. 502). Das and Teng (1998) furthermore point out that there is considerable overlap between normative control mechanisms and trust-building in the form of socialization, interaction and training, leading to a better understanding of each other and shared values. Thus, when control is predominantly of the normative type, where individuals are driven by internal commitment, strong identification with company goals and intrinsic satisfaction from work, acting appropriately becomes the goal and a normative frame is the consequence.

The third organizational policy concerns the socialization of newcomers. However experienced they may be, and regardless of their previous (possibly brilliant) track record, when newcomers enter a new organization, trust has to be built. People have to get to know one another. What exactly does he mean when he 
says "we will have to do this in a professional manner", or "You must have it finished in time"? For most tasks there is more than one way to do it, but it helps if people within a single organization all do it the same way. How is trust built with newcomers? The socialization of new personnel joining an organization is a process during which they are told "the way we do things around here". This process can vary from no formal induction at all to an intense and explicit process that never ends. The more explicit and intensive the socialization process for newcomers, the more quickly can frame resonance be achieved and the more quickly can trust be built between newcomers and existing colleagues. Also, once an organization has established the other two policies, it is only logical to make sure that newcomers understand the rationale of these policies. Although individuals' predispositions and prior experience will be important, an induction into the values, norms and behavioural practice specific to an organization should take place anyway. Stressing the importance of positive relational signalling requires a deliberate socialization.

Proposition 9 The more the organization introduces trust-enhancing organizational policies, such as a relationship-oriented culture, normative control and explicit and intensive socialization, the easier it is for trust to be built.

\section{Conclusions}

The key argument put forward in this study is that for interpersonal trust to be built in long-term work relations within organizations, both individuals in the relationship need to be guided by a stable normative frame; in other words, both should want to continue the relationship into the future. Thus, the stability of normative frames becomes a joint goal that is jointly produced within the relationship itself with positive relational signals, as well as within the organization as a whole by means of organizational policies. The theory shows that for interpersonal trust to be built (1) legitimate distrust situations must be removed through interest alignment arrangements; (2) both individuals must regularly perform actions that convey positive relational signals; (3) both individuals involved in a trouble situation must at least act in ways that are not perceived as negative relational signals, and (4) organizational policies must be put in place that stimulate frame resonance.

Interpersonal trust-building is best conceptualized as an interactive process in which both individuals learn about each other's trustworthiness in different situations. The theory of interpersonal trust-building developed in this study is based on two core assumptions:

1. Human behaviour is goal directed and rationality is strongly bounded by the fact that of the various potential goals, not all are given equal consideration.

2. Human behaviour is context dependent and guided by the normative context in which the individual is embedded.

On the basis of this limited set of assumptions about social goals, a theory of interpersonal trust-building is formulated, linking different analytical perspectives into a single framework that takes into account both social context (organizational 
policies) and individual behaviour. The theory of interpersonal trust-building takes into account important aspects of trust, such as the interactive nature of trust, the learning needed to achieve trust, the role of psychological mechanisms in trust decisions, the limits to trust, asymmetries between trust and distrust and the contextdependency of trust. The precarious nature of interpersonal trust-building is explained by the precarious nature of the normative frame needed for trust to be built and by the complexity of sending and-more importantly-receiving relational signals.

Several limitations to the proposed theory should be recognized. First, the theory presented here is limited to interpersonal trust and further research is needed to extend it to other forms of trust such as trust in organizations, institutions or social systems. A second limitation is that we have focused on work relations within organizations. We expect that the theory can be extended to all work relations since the need for stable normative frames to guide the behaviour of both involved holds for trust-building in all work relations. The underlying dynamics are therefore expected to be very similar, although it may be more difficult to introduce policies to enhance the trust-building when the individuals do not belong to the same organization. In addition, the culture-dependency of the normative frame may also make it more difficult to achieve frame resonance since it is not merely the fact that both individuals want to act appropriately that achieves frame resonance, but rather the actual content of what acting appropriately entails. Further research is needed to investigate the consequences of the proposed theory to inter-organizational work relations such as relations between clients, alliance relations and public-private partnership relations.

The theory developed in this study requires empirical testing to further deepen our understanding of the dynamics of interpersonal trust-building and the role of relational signals. In the course of this study, several propositions have been formulated as a foundation for further research to test the validity of the theory. The first stage would be to develop reliable and valid instruments for each of the constructs involved. The focus should be on actions, perceptions and conclusions, as shown in Fig. 1. When actions are interpreted for their relational signal, the perception of the receiver, as well as the intentions of the actor, should be studied.

Several types of research are needed, in particular experimental and observational to test the causal claims made. Event-based designs, studying trust and trouble events, are also needed. "[F]or such cases allow investigators and readers to observe the temporal unfolding and microdynamics of [relationship] management, as well as to ascertain statistically [dominant patterns] in numerically large samples..." (Morrill 1995, p. 2). Event-based research also enables studying the impact of the social context on the interaction (Morrill 1995; Wittek 1999). For example, testing proposition 8 would require both experiments to establish causation in controlled settings, as well as the study of trouble events in natural field settings. Within each event data would be collected on (1) the trustor's and trustee's perceptions of the signals in the trustee's behaviour, (2) the trustee's and trustor's perception of the signals in the trustor's behaviour, (3) the trustor's perception of the impact of the trouble event on the trust in the relationship and (4) the trustee's perception of the impact of the trouble event on the trust in the relationship. 
Case study research is needed to test for example proposition 2. Are all four conditions indeed necessary for interpersonal trust to be built successfully or do organizations exist that have built trust successfully without meeting all four conditions? Are there other conditions that can be shown to be needed for successful trust-building within organizations?

This article assumed, based on an extensive literature, that trust was important for cooperation and organizational performance. RST provides a theoretical basis why this may be so. Moran and Ghoshal (1999) showed that value is created and realized when new, novel resource deployments can be made. Lane and Maxfield (1996) showed that these innovations occur in "generative relations", in which some essential heterogeneity or distance between the participants exists while at the same time these participants have some shared directedness that makes them want to bridge the distance between them. Nooteboom (1999, p. 13) used the notion of "cognitive distance" to describe the same phenomenon, "if effectiveness of knowledge transfer is the product of novelty and intelligibility, this yields some optimal intermediate cognitive distance". Further research is warranted to test the hypothesis that the better a party's ability to deal with trust and trouble, the better he or she is at building and maintaining the network of generative relationships out of which novel resource deployments can be made. Also, the better each party in the relationship is at building trust and managing the stability of both his or her own and the other's normative frame, the larger the cognitive distance that can be bridged productively.

Finally, future research is needed to systematically study the impact of applying March's logics in decision-making, the logic of consequence and the logic of appropriateness (March 1994), on trust theory. Trust definitions and theory so far have focused on the logic of consequence, focusing on the consequences of putting trust in action, particularly the risks involved (for example, Deutsch 1973; Coleman 1990; Mayer et al. 1995; Rousseau et al. 1998). Trust-building also involves a logic of appropriateness, where the consideration for trust focuses on what is appropriate in the given situation, "to act appropriately", in other words a normative frame.

\section{References}

Ajzen, I., Dalto, C. A., \& Blyth, D. P. (1979). Consistency and bias in the attribution of attitudes. Journal of Personality and Social Psychology, 37, 1871-1876.

Archer, M. S. (1995). Realist social theory: The morphogenetic approach. Cambridge: Cambridge University Press.

Argyris, C. (1970). Intervention theory and method, a behavioral science view. Reading: AddisonWesley.

Augoustinos, M., \& Walker, I. (1995). Social cognition: An integrated introduction. London: Sage.

Bacharach, M., \& Gambetta D. (2001). Trust in signs. In K. S. Cook (Ed.), Trust in society (pp. 148-184). New York: Russell Sage Foundation.

Barber, B. (1983). The logic and limits of trust. Rutgers University Press.

Bies, R. J., \& Tripp, T. M. (1996). Beyond distrust: "Getting even" and the need for revenge. In R. M. Kramer \& T. R. Tyler (Eds.), Trust in organizations, frontiers of theory and research (pp. 246-260). Thousand Oaks: Sage Publications. 
Bond, C. F., Omar, A., Pitre, U., Lashley, B. R., Skaggs, L. M., \& Kirk, C. T. (1992). Fishy-looking liars: Deception judgment from expectancy violation. Journal of Personality and Social Psychology, 63, 969-977.

Bottom, W. P., Gibson, K., Daniels, S. E., \& Murnighan J. K. (2002). When talk is not cheap: Substantive penance and expressions of intent in rebuilding cooperation. Organization Science, 13, 497-513.

Bradach, J. L., \& Eccles, R. G. (1989). Price, authority and trust: From ideal types to plural forms. Annual Review of Sociology, 15, 97-118.

Coleman, J. S. (1990). Foundations of social theory. Cambridge: Harvard University Press.

Das, T. K., \& Teng, B. (1998). Between trust and control: Developing confidence in partner cooperation in alliances. Academy of Management Review, 23, 491-512.

Das, T. K., \& Teng, B. (2001). Trust, control and risk in strategic alliances: An integrated framework. Organization Studies, 22, 251-284.

Deutsch, M. (1973). The resolution of conflict: Constructive and destructive processes. New Haven: Yale University Press.

Dillard, J. P., Haunani Solomon, D., \& Samp, J. A. (1996). Framing social reality. The relevance of relational judgements. Communication Research, 23, 703-723.

Eckel, C. C., \& Wilson, R. K. (2004). Is trust a risky decision? Journal of Economic Behavior \& Organization, 55, 447-465.

Eisenhardt, K. M. (1985). Control: Organizational and economic approaches. Management Science, 31, 134-149.

Ferrin, D. L., Dirks, K. T., \& Shah, P. P. (2006). Direct and indirect effects of third-party relationships on interpersonal trust. Journal of Applied Psychology, 91, 870-883.

Fincham, F. D., \& Bradbury, T. N. (1987). Cognitive processes and conflict in close relationships: An attribution-efficacy model. Journal of Personality and Social Psychology, 53, 1106-1118.

Frank, R. H. (1988). Passions within reason, the strategic role of the emotions. New York: Norton.

Gabarro, J. J. (1978). The development of trust, influence and expectations. In A. G. Athos \& J. J. Gabarro (Eds.), Interpersonal behavior, communication and understanding in relationships (pp. 290-303). Englewood Cliffs: Prentice-Hall.

Gambetta, D. (1988). Mafia: The price of distrust. In D. Gambetta (Ed.), Trust, making and breaking cooperative relations (pp. 157-175). New York: Basil Blackwell.

Goffman, E. (1959). The presentation of self in everyday life. Garden City: Doubleday Anchor.

Gollwitzer, P. M., \& Moskowitz, G. B. (1996). Goal effects on action and cognition. In E. T. Higgins \& A. W. Kruglanski (Eds.), Social psychology: Handbook of basic principles (pp. 361-399). London: The Guildford Press.

Greenberg, J. (1990). Organizational justice: Yesterday, today and tomorrow. Journal of Management, 16, 399-432.

Hardin, R. (1993). The street-level epistemology of trust. Analyse \& Kritik, 14, 152-176.

Hardin, R. (2002). Trust and trustworthiness. New York: Russell Sage Foundation.

Hardin, R. (2004). Distrust: Manifestations and management. In R. Hardin (Ed.), Distrust, volume VIII in the Russell Sage Foundation series on trust (pp. 3-33). New York: Russell Sage Foundation.

Hirschman, A. O. (1970). Exit, voice and loyalty: Responses to decline in firms, organizations, and states. Cambridge: Harvard University Press.

Hollis, M. (1998). Trust within reason. Cambridge: Cambridge University Press.

Hoogervorst, J., Van der Flier, H., \& Koopman, P. (2004). Implicit communication in organisations, the impact of culture, structure and management practices on employee behavior. Journal of Managerial Psychology, 19, 288-311.

Hosmer, L. T. (1995). Trust: The connecting link between organizational theory and philosophical ethics. Academy of Management Review, 20, 379-403.

Johnson, D. W., \& Johnson, R. T. (1995). Social interdependence, cooperative learning in education. In B. B. Bunker \& J. Z. Rubin (Eds.), Conflict, cooperation and justice. San Francisco: Jossey-Bass.

Kahneman, D., \& Tversky, A. (2000). Choices, values, and frames. Cambridge: Cambridge University Press.

Kelley, H. H. (1973). The processes of causal attribution. American Psychologist, 28, 107-128.

Knight, F. (1921). Risk, uncertainty and profit. Boston: Houghton Mifflin.

Knights, D., Noble, F., Vurdubakis, T., \& Wilmott, H. (2001). Chasing shadows: Control, virtuality and the production of trust. Organization Studies, 22, 311-336.

Komorita, S. S., \& Parks, C. D. (1995). Interpersonal relations: Mixed-motive interactions. Annual Review of Psychology, 46, 183-207. 
Korsgaard, M. A., Schweiger, D. M., \& Sapienza, H. J. (1995). Building commitment, attachment, and trust in strategic decision-making teams: The role of procedural justice. Academy of Management Journal, 38, 60-84.

Kramer, R. M. (1999). Trust and distrust in organizations: Emerging perspectives, enduring questions. Annual Review of Psychology, 50, 569-598.

Kremer, J. F., \& Stephens, L. (1983). Attributions and arousal as mediators of mitigation's effect on retaliation. Journal of Personality and Social Psychology, 45, 335-343.

Kruglanski, A. W. (1996). Motivated social cognition: Principles of the interface. In E. T. Higgins \& A. W. Kruglanski (Eds.), Social psychology: Handbook of basic principles (pp. 493-520). London: The Guildford Press.

Kunda, G. (1992). Engineering culture, control and commitment in a Hightech Corporation. Philadelphia: Temple University Press.

Lane, C. (1998). Introduction: Theories and issues in the study of trust. In C. Lane \& R. Bachman (Eds.), Trust within and between organizations, conceptual issues and empirical applications (pp. 1-30). Oxford: Oxford University Press.

Lane, D., \& Maxfield, R. (1996). Strategy under complexity: Fostering generative relationships. Long Range Planning, 29, 215-231.

Larson, D. W. (2004). Distrust: Prudent, if not always wise. In R. Hardin (Ed.), Distrust (pp. 34-59). New York: Russell Sage Foundation.

Latané, B., \& L'Herrou, T. (1996). Spatial clustering in the conformity game: Dynamic social impact in electronic groups. Journal of Personality and Social Psychology, 70, 1218-1230.

Lewicki, R. J., \& Bunker, B. B. (1996). Developing and maintaining trust in work relationships. In R. M. Kramer \& T. R. Tyler (Eds.), Trust in organizations, frontiers of theory and research (pp. 114-139). Thousand Oaks: Sage Publications.

Lewin, K. (1936). Principles of topological psychology. New York: McGraw Hill.

Lewis, J. D., \& Weigert, A. (1985). Trust as a social reality. Social Forces, 63, 967-984.

Lindenberg, S. (1988). Contractual relations and weak solidarity: The behavioral basis of restraints on gain-maximization. Journal of Institutional and Theoretical Economics, 144, 39-58.

Lindenberg, S. (1993a). Club hierarchy, social metering and context instruction: Governance structures in response to varying self-command capital. In S. Lindenberg \& H. Schreuder (Eds.), Interdisciplinary perspectives on organization studies (pp. 195-220). Oxford: Pergamon.

Lindenberg, S. (1993b). Framing, empirical evidence and applications. In Jahrbuch für Neue Politische Ökonomie (pp. 11-35), Mohr, Tübingen.

Lindenberg, S. (1997). Grounding groups in theory: Functional, cognitive and structural interdependencies. Advances in Group Processes, 14, 281-331.

Lindenberg, S. (1998). Solidarity: Its microfoundations and macrodependence. A framing approach. In P. Doreian \& T. Fararo (Eds.), The problem of solidarity, theories and models (pp. 61-112). London: Gordon and Breach.

Lindenberg, S. (2000). It takes both trust and lack of mistrust: The workings of cooperation and relational signaling in contractual relationships. Journal of Management and Governance, 4, 11-33.

Lindenberg, S. M. (2003). Governance seen from a framing point of view: The employment relationship and relational signalling. In B. Nooteboom \& F. E. Six (Eds.), The trust process, empirical studies of the determinants and the process of trust development (pp. 37-57). Cheltenham: Edward Elgar.

Luhmann, N. (1979). Trust and power. Chicester: John Wiley.

March, J. G. (1994). A primer on decision making, how decisions happen. New York: The Free Press.

Mayer, R. C., Davis, J. H., \& Schoorman, F. D. (1995). An integrative model of organizational trust. Academy of Management Review, 20, 703-734.

McAllister, D. J. (1995). Affect- and cognition-based trust as foundations for interpersonal cooperation in organizations. Academy of Management Journal, 38, 24-59.

McClintock, C. G. (1972). Social motivation, a set of propositions. Behavioral Science, 17, 438-454.

McEvily, B., Perrone, V., \& Zaheer, A. (2003). Trust as an organizing principle. Organization Science, 14, 91-103.

Messick, D. M., \& Kramer, R. M. (2001). Trust as a form of shallow morality. In K. S. Cook (Ed.), Trust in society (pp. 89-118). New York: Russell Sage Foundation.

Mischel, W., Cantor, N., \& Feldman, S. (1996). Principles of self-regulation: The nature of willpower and self-control. In E. T. Higgins \& A. W. Kruglanski (Eds.), Social psychology: Handbook of basic principles (pp. 329-360). London: The Guildford Press. 
Möllering, G. (2001). The nature of trust: from Georg Simmel to a theory of expectation, interpretation and suspension. Sociology, 35, 403-420.

Moon, H., \& Conlon, D. E. (2002). From acclaim to blame: Evidence of a person sensitivity decision bias. Journal of Applied Psychology, 87, 33-42.

Moran, P., \& Ghoshal, S. (1999). Markets, firms and the process of economic development. Academy of Management Review, 24, 390-412.

Morrill, C. (1995). The executive way: Conflict management in corporations. Chicago: Chicago University Press.

Mühlau, P. (2000). The governance of the employment relation, a relational signaling perspective. Doctoral dissertation, University of Groningen.

Mühlau, P., \& Lindenberg, S. (2003). Efficiency wages: Signals or incentives? An empirical study of the relationship between wages and commitment. Journal of Management and Governance, 7, 384-400.

Nooteboom, B. (1999). Inter-firm alliances, analysis and design. London: Routledge.

Nooteboom, B. (2002). Trust: Forms, foundations, functions, failures and figures. Cheltenham: Edward Elgar.

Olson, J. M., Roese, N. J., \& Zanna, M. P. (1996). Expectancies. In E. T. Higgins \& A. W. Kruglanski (Eds.), Social psychology: Handbook of basic principles (pp. 211-238). London: The Guildford Press.

Pillutla, M. M., Malhotra, D., \& Murnighan, J. K. (2003). Attributions of trust and the calculus of reciprocity. Journal of Experimental Social Psychology, 39, 448-455.

Pruitt, D. G., \& Rubin, J. Z. (1986). Social conflict, escalation, stalemate and settlement. New York: Random House.

Ring, P. S., \& Van de Ven, A. H. (1994). Developmental processes of cooperative interorganizational relationships. Academy of Management Review, 19, 90-118.

Robbins, R. W., Mendelsohn, G. A., Connell, J. B., \& Kwan, V. S. Y. (2004). Do people agree about the causes of behavior? A social relations analysis of behavior ratings and causal attributions. Journal of Personality and Social Psychology, 86, 334-344.

Ross, L. (1977). The intuitive psychologist and his shortcomings: Distortions in the attribution process. In L. Berkowitz (Ed.), Advances in experimental social psychology (Vol. 10, pp.173-220). New York: Academic Press.

Ross, W., \& LaCroix, J. (1996). Multiple meanings of trust in negotiation theory and research: A literature review and integrative model. The International Journal of Conflict Management, 7, 314360 .

Rousseau, D. M., Sitkin, S. B., Burt, R. S., \& Camerer, C. (1998). Not so different after all: A crossdiscipline view of trust. Academy of Management Review, 23, 393-404.

Schein, E. H. (1992). Organizational culture and leadership, second edition. San Francisco: Jossey-Bass.

Schelling, T. C. (1960). The strategy of conflict. Cambridge: Harvard University Press.

Schneider, W., \& Shiffrin, R. M. (1977). Controlled and automatic human information processing: I. Detection search and attention. Psychological Review, 84, 1-66.

Sears, D. O. (1983). The person-positivity bias. Journal of Personality and Social Psychology, 44, $233-250$

Shapiro, S. P. (1987). The social control of impersonal trust. American Journal of Sociology, 93, 623658.

Shiffrin, R. M., \& Schneider, W. (1977). Controlled and automatic human information processing: II. Perceptual learning, automatic attending, and a general theory. Psychological Review, 84, 127-190.

Shiffrin, R. M., \& Schneider, W. (1984). Automatic and controlled processing revisited. Psychological Review, 91, 269-276.

Six, F. E., \& Nooteboom, B. (2003). Conclusions. In B. Nooteboom \& F. E. Six (Eds.), The trust process, empirical studies of the determinants and the process of trust development (pp. 223-230). Cheltenham: Edward Elgar.

Staw, B. M. (1976). Knee-deep in the big muddy: A study of escalating commitment to a chosen course of action. Organizational Behaviour and Human Performance, 16, $27-44$.

Staw, B. M. (1997). The escalation of commitment: An update and appraisal. In Z. Shapira (Ed.), Organizational decision making (pp. 191-215). Cambridge: Cambridge University Press.

Tazelaar, M. J. A., Van Lange, P. A. M., \& Ouwerkerk, J. W. (2004). How to cope with "noise" in social dilemmas: The benefits of communication. Journal of Personality and Social Psychology, 87, 845859. 
Tsui, A. S., Pearce, J. L., Porter, L. W., \& Tripoli, A. M. (1997). Alternative approaches to the employeeorganization relationship: Does investment in employees pay off? Academy of Management Journal, 40, 1089-1121.

Tversky, A., \& Kahneman, D. (1974). Judgment under uncertainty: Heuristics and biases. Science, 185, 1124-1131.

Tyler, T. R. (1989). The psychology of procedural justice: A test of the group-value model. Journal of Personality and Social Psychology, 57, 830-838.

Tyler, T. R., \& Kramer, R. M. (1996). Whither trust? In R. M. Kramer \& T. R. Tyler (Eds.), Trust in organizations, frontiers of theory and research (pp. 1-15). Thousand Oaks: Sage Publications.

Van Lange, P. A. M., Ouwerkerk, J. W., \& Tazelaar, M. J. A. (2002). How to overcome the detrimental effect of noise in social interaction: The benefits of generosity. Journal of Personality and Social Psychology, 82, 768-780.

Van Lange, P. A. M., \& Visser, K. (1999). Locomotion in social dilemmas: How people adapt to cooperative, tit-for-tat and noncooperative partners. Journal of Personality and Social Psychology, 77, 762-773.

Weber, J. M., Malhotra, D., \& Murnighan, J. K. (2005). Normal acts of irrational trust: Motivated attributions and the trust development process. Research in Organizational Behavior, 26, 75-101.

Wells, C. V., \& Kipnis, D. (2001). Trust, dependency, and control in the contemporary organization. Journal of Business and Psychology, 15, 593-603.

White, P. A. (1988). Causal processing: Origins and development. Psychological Bulletin, 104, 36-52.

Whitener, E. M., Brodt, S. E., Korsgaard, M. A., \& Werner, J. M. (1998). Managers as initiators of trust: An exchange relationship framework for understanding managerial trustworthy behavior. Academy of Management Review, 23, 513-530.

Wielers, R. J. J. (1997). The wages of trust: The case of child minders. Rationality and Society, 9, 351371.

Williamson, O. E. (1993). Calculativeness, trust and economic organization. Journal of Law and Economics, 36, 453-486.

Wittek, R. P. M. (1999). Interdependence and informal control in organizations. Doctoral dissertation, University of Groningen.

Wittek, R. P. M., Van Duijn, M. A. J., \& Snijders, T. A. B. (2003). Frame decay, informal power, and the escalation of social control in a management team: A relational signaling perspective. Research in the Sociology of Organizations, 20, 355-380.

Zand, D. E. (1972). Trust and managerial problem solving. Administrative Science Quarterly, 17, 229239.

Zand, D. E. (1997). The leadership triad, knowledge, trust and power. New York: Oxford University Press.

Zucker, L. G. (1986). Production of trust: Institutional sources of economic structure, 1840-1920. Research in Organizational Behavior, 8, 53-111.

Zucker, L. G., Darby, M. R., Brewer, M. B., \& Peng, Y. (1996). Collaboration structure and information dilemmas in biotechnology: Organizational boundaries as trust production. In R. M. Kramer \& T. R. Tyler (Eds.), Trust in organizations, frontiers of theory and research (pp. 90-113). Thousand Oaks: Sage Publications.

\section{Author Biography}

Frédérique E. Six is lecturer of Governance and Organization at the department of Public Administration and Organization Science at the VU University Amsterdam, the Netherlands. She received her Ph.D. in Management from Erasmus University Rotterdam and her MBA from INSEAD. Her research interests are the management of trust and integrity within organizations. 